\title{
OS ESPAÇOS NÃO-FORMAIS DE APRENDIZAGEM E AS CONTRIBUIÇÕES PARA A CONSOLIDAÇÃO DE UM NOVO FAZER PEDAGÓGICO NO ENSINO DE ZOOLOGIA.
}

\author{
Apresentação: Comunicação Oral
}

Suellen Claudia de Barros ${ }^{1}$; Andressa Rodrigues dos Santos ${ }^{2}$; Dayana Maria Serafim da Silva ${ }^{3}$ Suellen Tarcyla da Silva Lima ${ }^{4}$

\begin{abstract}
Resumo
Muito se tem discutido a cerca dos processos de ensino-aprendizagem em Ciências, os desafios da sociedade atual envolvem, entre outras coisas, transformar as inúmeras informações de um mundo globalizado em conhecimentos. Para isso, o ensino de Ciências deve estimular os estudantes a observarem, pesquisarem e questionarem. A biologia é umas das ciências da natureza. Dentre as diversas áreas de conhecimento que esta ciência possui, a Zoologia é a que permite compreender os aspectos fisiológicos, morfológicos e relações ecológicas que caracterizam os diversos filos, no entanto, na maioria das vezes, a Zoologia é abordada de forma fragmentada, e raramente os estudantes têm uma aproximação com os espaços alternativos de Educação que busquem aproximar os conteúdos vivenciados em Zoologia de maneira prática. Nesse sentido, o trabalho propôs relacionar as aulas teóricas de Zoologia com as práticas, por meio de um espaço não-formal de educação, por entender que nesse espaço pode haver um fortalecimento do processo de ensino-aprendizagem da Zoologia no Ensino Fundamental. O estudo teve um enfoque qualitativo, e foi realizado no primeiro e segundo semestres de 2016, com 87 estudantes dos anos finais do Ensino Fundamental, e consistiu em 3 etapas, nas quais, a primeira e a terceira, foram vivenciadas em uma instituição privada, enquanto a segunda, no Zoológico Dois Irmãos, ambos localizados no Recife-PE. De acordo com os resultados, observou-se uma construção significativa de conhecimentos por parte dos alunos, pois, em todas as etapas houve grande interação, além disso, os estudantes puderam ser sensibilizados em relação a importância da conservação das espécies, da preservação do meio ambiente, bem como a importância que todos os seres vivos possuem para o ecossistema e equilíbrio da natureza. Assim, ao interligar o teórico ao prático, pudemos concluir que todas as etapas, desde as aulas expositivas dialogadas realizadas, passando pelas discussões realizadas no Colégio, até as excursões didáticas, proporcionaram aumento significativo na construção do conhecimento dos estudantes em relação as temáticas que envolvem a Zoologia.
\end{abstract}

\footnotetext{
1 Professora de Biologia e Ciências e Graduada em Licenciatura em Ciências Biológicas, Universidade Federal Rural de Pernambuco, suellen_claudia@hotmail.com

2 Professora de Ciências e Graduanda do curso de Licenciatura em Ciências Biológicas, Universidade Federal Rural de Pernambuco, andressa.biology@gmail.com.

3 Professora de Biologia e Ciências e mestranda em Ciências Veterinárias, Universidade Federal Rural de Pernambuco, dayanamserafim@gmail.com

4 Doutoranda no Programa de Pós-Graduação em Ensino das Ciências, Universidade Federal Rural de Pernambuco, suellen_tarcyla@hotmail.com
} 
Palavras-Chave: Ensino-aprendizagem, Zoologia, Espaço não-formal.

\section{Introdução}

Muito se tem discutido a cerca do ensino de Ciências, pois, na sociedade em que vivemos é preciso que saibamos transformar as inúmeras informações dispersadas pelos diferentes meios de comunicação, em um conhecimento que seja capaz de transformar e sensibilizar, permitindo assim, tornar as pessoas mais críticas e humanizadas. Neste sentido, o ensino de Ciências pode ser considerado uma poderosa ferramenta, devendo estar associado não apenas aos conhecimentos científicos, mas também à difusão de valores e atitudes (PRAIA, GIL-PEREZ, VILCHES, 2007). Sendo assim, o ensino de Ciências busca estimular os estudantes a observarem, pesquisarem, questionarem, analisarem os problemas, levando, consequentemente, à construção de ações positivas sobre si mesmos e sobre a sociedade a qual estão inseridos (BIZZO, 2007).

A Zoologia é uma das áreas das Ciências Biológicas que está presente tanto no Ensino Fundamental, quanto no Ensino Médio, o ensino dessa disciplina envolve, entre outras coisas, um enfoque evolutivo e ecológico, que é importante para compreensão da história zoológica das espécies, uma vez que coloca em foco as diversas formas, estruturas, órgãos e sistemas dos diversos grupos, e evidencia as características que permitem a adaptação dos grupos ao meio ambiente a qual pertencem.

A zoologia como área de ensino, oferece ferramentas de compreensão de sucessão ecológica e permite compreender as diversas formas de relações existentes na Biosfera (SONIA; ROSSO,2014). Entretanto, a Zoologia é, muitas vezes, abordada na Educação Básica de forma fragmentada, sem mostrar as relações com os períodos geológicos, os hábitos alimentares, os hábitats, o comportamento animal, a evolução, a anatomia comparada e as classificações taxonômicas.

Por outro lado, alguns espaços alternativos de educação podem contribuir para facilitar o processo de conexão entre estes diversos aspectos (KRASILCHIK,2005), sendo assim, o presente trabalho propôs relacionar as aulas teóricas de Zoologia com vivências práticas em e um espaço não-formal de educação, interconectando assim, as diferentes formas de perceber e vivenciar os conteúdos, evidenciando a importância desses espaços como instrumento potencializador do processo de ensino-aprendizagem da Zoologia no Ensino Fundamental.

\section{Fundamentação Teórica}

Caracterização dos Espaços não-formais de Educação 
De acordo com Brandão (1985), a educação pode ser compreendida como todo conhecimento adquirido com a vivência no meio social, onde o ato educacional pode ocorrer nos mais variados ambientes e situações como, por exemplo, nos transportes coletivos, em casa, na igreja, na família, ou seja, as diversas interações e situações, fazem parte deste processo de aprendizagem, sendo assim,

\footnotetext{
Ninguém escapa da educação. Em casa, na rua, na igreja ou na escola de um modo ou de muitos, todos nós envolvemos pedaços da vida com ela: para aprender, para ensinar, para aprender-e-ensinar. Para saber, para fazer, para ser ou para conviver, todos os dias misturamos a vida com a educação. Com uma ou com várias: educação? Educações (BRANDÃO, 1985, p. 7).
}

Entretanto, existem lugares distintos nos quais acontecem a produção do conhecimento, esses lugares representam espaços alternativos que contribuem para a formação de cidadãos ativos na sociedade. Desde 1980, começou a surgir o movimento de expansão desses espaços alternativos para a educação, quando a Unesco propôs "A ciência para todos", que tinha uma proposta de compromisso social para qualificação de todas as etapas da vida humana, uma vez que a Ciência está interligada com o desenvolvimento da sociedade, sendo ela um produto da mente humana (CHASSOT, 2003; MARANDINO et al, 2009).

Nesse sentido, os espaços de educação não-formais, segundo Marandino e colaboradores (2009), é qualquer espaço, diferente da escola, onde pode ocorrer uma ação educativa, porém, é necessário o entendimento por parte dos professores de que estes espaços apresentam essa característica: a de ampliar a popularização da cultura científica; sendo esta conexão entre os espaços não-formais e formais de educação fundamental para o entendimento de como se dá o processo de construção da Ciência (JACOBUCCI ,2008).

Para Jacobucci (2008), existem dois tipos de espaços não formais: os espaços institucionalizados, que dispõe de planejamento, estrutura física e monitores qualificados para a prática educativa dentro destes espaços, exemplos desses espaços são: os jardins botânicos, zoológicos e museus; em contrapartida, os espaços não institucionalizados são aqueles que não dispõem de uma estrutura preparada para este fim, contudo, sendo a atividade bem planejada, poderá se tornar um espaço educativo de construção científica como, por exemplo, as praças públicas, áreas verdes nas proximidades da escola e lagos.

\section{Os Zoológicos}

Os zoológicos são espaços que contém coleção de animais silvestres em cativeiro sendo exibidos, podendo ser pública ou particular, possuindo animais exóticos ou nativos. São espaços institucionalizados destinados à exposição e à pesquisa de animais vivos que estão, 
geralmente, correndo risco de extinção. É um espaço lúdico, interativo e que desperta interesse de crianças e adultos, independente da idade, pois, os visitantes podem observar os animais em tamanho real, seu comportamento, sua alimentação e suas características (ACHUTT, 2003).

A única função dos zoológicos, em sua maioria, não é só a exposição de animais, sua função passa a ter maior significado quando sensibiliza os visitantes quanto à ação predatória do homem ao interferir no habitat natural dos animais, podendo assim, torná-los susceptíveis à extinção. Em um zoológico, podemos encontrar espécies diversas de variados lugares do mundo, porém, muitas vezes, o alto investimento para criação do ambiente ideal ou hábitat perfeito para adaptação daquela espécie trazida de outra região, nem sempre se torna viável para alguns zoológicos (ACHUTT, 2003).

Entretanto, os zoológicos não podem ser considerados uma novidade da vida moderna, o ato de colecionar animais em cativeiro vem desde a antiguidade. Inicialmente, esta prática tinha a função de realçar o poder dos líderes e proporcionar ao povo uma forma de diversão oferecida pelos animais em exposição, muitos destes animais eram adotados por circos e sofriam devido aos maus tratos e péssimas condições à eles impostas, situação esta que, infelizmente, ainda hoje, podem ser encontradas.

Contudo, com o passar do tempo, com a evolução da ciência e com o crescente interesse dos cientistas em entender melhor a natureza, os animais selvagens tornaram-se alvo do interesse científico numa busca não só de compreensão do seu modo de vida, mas, também para possibilitar a preservação dos mesmos e dos recursos naturais a eles relacionados. Os zoológicos, além da exposição da fauna, podem também evidenciar a flora, além disso, estes espaços favorecem a difusão da informação de cunho científico, geralmente, através de placas informativas presentes nos diferentes hábitats construídos para abrigar os animais. Alguns zoológicos apresentam, também, em sua estrutura, hospital ou ambientes veterinários voltados à recuperação de animais feridos, bem como áreas direcionadas à readaptação destes animais ao meio ambiente de origem, quando assim possível (ACHUTT, 2003).

\section{O Zoológico Dois Irmãos}

O Zoológico Dois irmãos do Recife foi fundado em 1916, nas terras do Engenho Dois Irmãos, pertencente aos irmãos Antônio e Tomás Lins Caldas, desse parentesco veio a origem do nome, que também batizou o bairro, o engenho foi um dos primeiros fundados no Brasil, no ano de 1577 (SECRETARIA DE MEIO AMBIENTE E SUSTENTABILIDADE, GOVERNO DE PERNAMBUCO). 
Inicialmente, o espaço era administrado pela Prefeitura do Recife, e em 1935 o Horto Florestal passou a pertencer à Fundação do Instituto de Pesquisas Agronômicas - IPA, mas, só em 1939 transformou-se no Jardim Zoobotânico de Dois Irmãos, cujo primeiro diretor foi o professor e ecólogo João de Vasconcelos Sobrinho; a partir do ano de 1969, passou a ser administrado pela Empresa Pernambucana de Turismo - EMPETUR, vinculada à Secretaria de Turismo, Cultura e Esportes, e em 1987 foi transformado em Reserva Ecológica pela Lei n 9.989 de 13 de janeiro de 1989 (idem).

O título de "Parque Dois Irmãos" só foi instituído em 7 de julho de 1997, abrangendo uma área de 387,4 hectares, que incluía um fragmento de Mata Atlântica com os açudes do Prata, do Meio, e o de Dois Irmãos, além de 14 hectares de área construída do Horto Zoobotânico. No entanto, só em 1998, o Governo do Estado homologou a Lei no 11.622, transformando a Reserva Ecológica de Dois Irmãos em Parque Estadual Dois Irmãos. E Em 2006, a área do Parque foi reduzida a 384,42 hectares, através da Lei №. 13.159. Atualmente, o parque está subordinado à Secretaria de Meio Ambiente e Sustentabilidade do Estado Semas (idem).

O Parque Estadual Dois Irmãos tem uma área de 384,42 hectares, sendo 14 hectares ocupados pelo Zoológico do Recife. A reserva do Parque, considerada uma das maiores áreas de Mata Atlântica de Pernambuco, proporciona aos visitantes conhecer o ecossistema, suas plantas e seus animais nativos, como preguiças, saguis, quatis, capivaras, além de uma enorme variedade de pássaros. O Zoológico Dois Irmãos, apresenta enquanto missão: a conservação das espécies e o conhecimento da natureza, tais objetivos podem ser alcançados através da vivência e do contato direto com a fauna e flora, fazendo com que o zoo deixe de ser "vitrine de animais" para se transformar em centro de conservação da natureza (idem).

Atualmente, no zoológico vivem cerca de 600 animais entre répteis, aves e mamíferos, tanto nativos do Brasil quanto exóticas, são eles:

- Repteis: Cágado-do-Nordeste,Iguana,Jabuti Tigre d' água, Jibóia, Suaçubóia, Sucuri, Píton-de-Burma (albina) e Jacaré-de-papamarelo;

- Aves: Arara-azul, Arara-vermelha, Avestruz, Ararajuba, Ema, Emu, Harpia, Guará, $\underline{\text { Pelicano, }} \underline{\text { Mutum-cavalo, }}$ Mutum-de-bico-azul, Mutum-de-bico-amarelo, Mutumtopete-de-pedra, Tucano-toco, Uiraçu-Falso, Cisne-negro;

- Mamíferos: Anta, Babuíno Sagrado, Camelo, Suçuarana, puma, Macaco-aranha-decara-vermelha, Macaco-prego-galego, Cervo-nobre, Cervo-sambar, $\underline{\text { Chimpanzé, Gato- }}$ $\underline{\text { do-mato, Guaxinim, Hipopótamo, Jaguatirica, Jupará, Leão, Lontra, Macaco-aranha- }}$ de-cara-preta, Macaco-aranha-de-testa-branca, Macaco-barrigudo, Macaco-prego, 
Onça-preta, Papa-mel, Coandu, ouriço-cacheiro, Babuíno-verde, Tamanduá-mirim, Tamanduá-bandeira, Tigre-siberiano, Urso-pardo (idem).

\section{Material e Métodos}

O estudo teve um enfoque qualitativo, e foi realizado no primeiro e segundo semestres de 2016, com 87 estudantes das séries finais do Ensino Fundamental, sendo 33 alunos do $6^{\circ}$ ano, 24 do $7^{\circ}$ ano, 18 do $8^{\circ}$ ano e 12 do $9^{\circ}$ ano de uma instituição privada. A pesquisa apresentou três etapas, onde a primeira e a terceira foram desenvolvidas em uma instituição de educação básica privada; e a segunda no Zoológico Dois Irmãos, ambos localizados no Recife-PE.

A primeira etapa foi realizada entre os meses de maio e junho e consistiu em aulas expositivas dialogadas, onde foram trabalhados os conteúdos referentes aos diferentes nichos ecológicos, habitats, hábitos alimentares e diferenças morfológicas entre os principais grupos de vertebrados (peixes, anfíbios, repteis, aves e mamíferos), bem como a evolução e a relação desta com os períodos geológicos, e classificações taxonômicas; aproveitamos a oportunidade para abordar o bem-estar e o tráfico animal.

A segunda etapa foi realizada no mês de outubro, no Zoológico Dois Irmãos, esta etapa consistiu na observação dos ambientes e dos animais expostos, com o intuito de estabeleceram uma relação com o que foi mencionado nas aulas teóricas e a realidade posta, para direcionar a percepção dos estudantes às questões destacadas em sala de aula, os alunos tiverem que responder um questionário, contendo seis questões de cunho dissertativo, cuja respostas seriam obtidas por meio da excursão didática nesse espaço. O Parque Dois Irmãos não possui representares das classes Peixes e Anfíbios, então, o direcionamento no espaço, foram para as classes Reptilia, Aves e Mammalia.

A terceira etapa, também realizada no mês de outubro, na referida escola e consistiu em discussões para a associação dos conceitos das aulas teóricas com as observações da aula prática.

Para garantir o anonimato dos sujeitos da pesquisa, atribuímos a letra "E", inicial da palavra "estudante", seguida de uma numeração para facilitar a identificação dos mesmos.

\section{Resultados e Discussão}

Desde as aulas expositivas dialogadas buscamos a sensibilização dos estudantes em relação a importância da conservação das espécies, da preservação do meio ambiente e a importância que todos os seres vivos possuem para o ecossistema e equilíbrio da natureza.

$\mathrm{Na}$ primeira etapa, durante as aulas expositivas dialogadas, foram evidenciadas a 
conexão entre os temas que estão presentes na Zoologia como, por exemplo, os hábitats, hábitos, taxonomia, tráfico animal, a evolução, dentre outros. E, a partir dessa etapa, foi observado o crescente interesse dos estudantes em aprender e participar desse processo, uma vez que eles constantemente eram levantados questionamentos, gerando discussões muito proveitosas.

Zabala (1998), afirma a importância de aguçar a curiosidade dos estudantes, fazendo com que criem motivação para aprender, através da problematização dos conceitos e conteúdos vivenciados, tornando-os, dessa forma, interessante e, ao mesmo tempo, não tirando o sabor da descoberta. Contudo, para isso, é necessário que o professor domine, com segurança, o conteúdo a ser trabalhado bem como, o mesmo deve conhecer as diferentes estratégias que podem ser empregadas na construção do conhecimento, favorecendo as múltiplas inteligências e diferentes perfis que compõe a pluralidade de uma sala de aula, só assim, será possível planejar aulas realmente interessantes, instigantes, fazendo conexões com o mundo exterior e provocando na turma a busca por respostas, afinal é esse exercício que conduz a aprendizagem significativa dos alunos.

A segunda etapa foi a mais interativa, pois cerca de 65\% dos estudantes (56 estudantes), nunca haviam visitado o zoológico, portanto, foi um momento de muitas descobertas e aprendizagem, levando em consideração que a maioria dos estudantes só conhecia alguns animais presentes no espaço por meio de ilustrações presentes nos livros didáticos.

Diante deste fato, ressaltamos mais uma vez a importância de determinados espaços não-formais, embora o ideal fosse que os animais estivessem livres na natureza e pudessem ser observados in loco, o zoológico permite esta aproximação, possibilitando que os alunos construam uma visão mais realista a respeito dos aspectos morfológicos e comportamentais dos animais, estimulando a ampliação da percepção por parte dos estudantes em relação ao ambiente e suas interconexões. Sendo assim, o zoológico tem a função de informar sobre caráter taxonômico, divulgar a diversidade das espécies e suas adaptações para a vida, tratamse também de instituições de pesquisa, que realizam procriação de espécies ameaçadas de extinção, além disso, são excelentes oportunidades de promover a educação ambiental (GARCIA, 2008).

$\mathrm{Na}$ terceira etapa do trabalho, realizada na escola, nos reunimos com os estudantes para discutirmos sobre a importância da excursão didática e as respostas que eles apresentaram no questionário sobre essa visita. Segue abaixo um quadro que traz alguns resultados obtidos através dos questionários, bem como a interpretação dos mesmos. 
Quadro 1 - Resultados e interpretação dos mesmos obtidas através das análises das respostas dos estudantes.

\begin{tabular}{|c|c|c|}
\hline Perguntas & Resposta dos Estudantes & Interpretação \\
\hline $\begin{array}{l}\text { Questão 1: Catalogar } \\
10 \text { espécies de } \\
\text { animais, presentes no } \\
\text { Zoológico } \\
\text { Irmãos, de } \\
\text { classe cada } \\
\text { vertebrados (Repteis, } \\
\text { Aves e mamíferos), } \\
\text { mencionando a } \\
\text { classificação } \\
\text { taxonômica, } \\
\text { diferenças } \\
\text { morfológicas } \\
\text { observadas, hábitos } \\
\text { alimentares, nichos } \\
\text { ecológicos e habitats. }\end{array}$ & 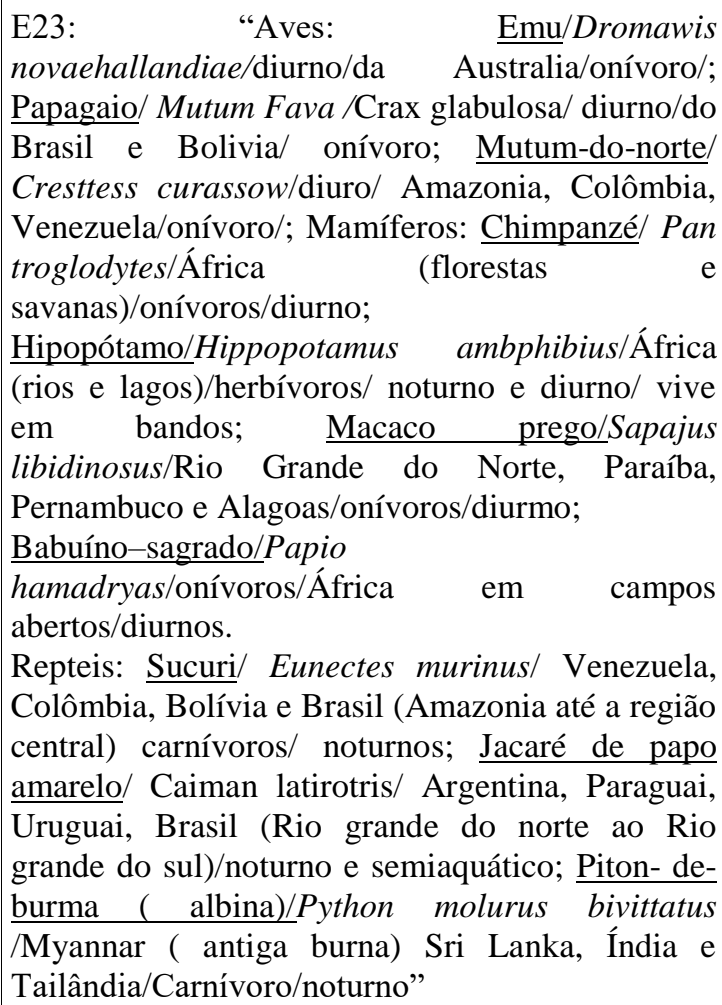 & $\begin{array}{l}\text { Todos os estudantes que foram para } \\
\text { excursão didática, responderam de } \\
\text { forma concisa e correta essa } \\
\text { questão, pois com os } \\
\text { conhecimentos construídos nas } \\
\text { aulas, presença do monitor do } \\
\text { zoológico ao longo da excursão e as } \\
\text { plaquinhas que descreviam os } \\
\text { animais, eles responderam o } \\
\text { relatório e discutiram os resultados } \\
\text { em sala. }\end{array}$ \\
\hline $\begin{array}{l}\text { Questão 2: Qual a } \\
\text { importância } \\
\text { Zoológico para a } \\
\text { conservação das } \\
\text { espécies? E qual a } \\
\text { relação do Zoológico } \\
\text { com o tráfico animal? }\end{array}$ & $\begin{array}{l}\text { E44: "Eles pegam os animais que estão } \\
\text { ameaçados de extinção. Para fazer com que os } \\
\text { animais em extinção procriem e os animais que } \\
\text { foram roubados da natureza pelos traficantes e } \\
\text { estão doentes fiquem melhores." }\end{array}$ & $\begin{array}{l}\text { Os estudantes entenderam que os } \\
\text { zoológicos não são apenas parques } \\
\text { de exposição de animais. E assim, } \\
\text { responderam que são espaços de } \\
\text { conservação das espécies, } \\
\text { propiciando a pesquisa e a educação } \\
\text { para o público, auxilia os animais } \\
\text { que estão em extinção, pois realiza } \\
\text { reprodução em cativeiro. }\end{array}$ \\
\hline
\end{tabular}

Questão 3: Cite E2: "Jiboia, Sucuri, Arara, Anta, Macaco-prego Foram citados: Jiboia, Sucuri, alguns animais da galego" $\quad$ Arara, Anta, Macaco-prego galego \begin{tabular}{ll|l} 
fauna Brasileira & e outros.
\end{tabular}

encontrados no

Zoológico Dois

Irmãos.

Questão 4: Qual a E80: “Os zoológicos são ambientes mais artificiais Eles souberam diferenciar ambos os diferença entre os e os santuários mais naturais. Os santuários são espaços, onde informaram que seria zoológicos e os melhores pois as condições são mais favoráveis e melhor um santuário, pois se santuários? $\quad$ o zoológico os animais são mantidos em cativeiro assemelha mais ao habitat natural e e mostrados para o público."

isso seria benéfico, pois os animais não ficariam estressados demasiadamente, mas, infelizmente ainda não há santuários de iniciativas públicas.

Questão 5: Fale sobre E32: "É um zoológico grande e bonito e cuidam Nessa questão, os alunos o Zoológico Dois bem dos animais. O zoológico Dois irmãos do responderam contando a história do Irmãos. Recife, foi fundado em 1916 nas terras do zoológico, desde o ano da criação, o Engenho Dois Irmãos, por isso que tem o nome motivo do espaço ter trocado de 


\begin{tabular}{|c|c|c|}
\hline & $\begin{array}{l}\text { dois irmãos. Tem a parte da floresta atlântica, e a } \\
\text { parte onde ficam os animais em cativeiro, é muito } \\
\text { grande e antigo. É muito importante, pois os } \\
\text { animais não entram em extinção quando estão lá. } \\
\text { O zoológico Dois irmãos é grande e bonito, mas já } \\
\text { morreram muitos animais." }\end{array}$ & $\begin{array}{l}\text { nome várias vezes, e a extensão do } \\
\text { parque. }\end{array}$ \\
\hline $\begin{array}{l}\text { Questão 6: Fale sobre } \\
\text { o comportamento de } \\
\text { cadaranimal } \\
\text { observado. }\end{array}$ & $\begin{array}{l}\text { E20: "Avestruz: Estava olhando para nós, eu } \\
\text { pensei que fosse para sair na foto; Chipanzé: } \\
\text { Andando para o lado e para o outro da jaula; } \\
\text { Leão: dormindo; Lontra: estava tirando um } \\
\text { cochilo; Onça pintada: Agitada, nervosa por causa } \\
\text { do barulho da turma; Babuíno sagrado: Sentado } \\
\text { com o pé na grade; Jacaré de papo amarelo: Se } \\
\text { escondendo perto de um tronco na água. }\end{array}$ & $\begin{array}{l}\text { De modo geral, responderam que } \\
\text { muitos animais realizavam } \\
\text { movimentos repetitivos, por } \\
\text { exemplo, alguns primatas que } \\
\text { estavam andando de um lado para o } \\
\text { outro da jaula. O Avestruz estava } \\
\text { fazendo pose para tirar foto. O leão } \\
\text { estava dormindo porque é um } \\
\text { animal de habito noturno, assim } \\
\text { como outros grandes mamíferos, } \\
\text { mais especificamente os felinos. A } \\
\text { Sucuri, estava "gorda" porque tinha } \\
\text { acabado de comer, que a Lontra } \\
\text { estava nadando por causa do calor. }\end{array}$ \\
\hline
\end{tabular}

Fonte: As autoras.

Sobre as respostas obtidas na primeira questão, conseguimos perceber que os zoológicos mais modernos não são mais como uma vitrine de animais, mas passaram a desempenhar outras funções como, conservar as espécies ameaçadas, campo de pesquisas, fontes de dados e divulgação (ACHUTT, 2003).

Em relação ao tráfico animal, eles responderam de forma genérica, que muitos animais são capturados das matas, para serem vendidos ilegalmente e o zoológico fornece serviços de cuidados e tratamentos desses animais que, muitas vezes, não tem condições de voltar ao hábitat natural. Trata-se de uma prática comum em diversos países onde, a prática geral, é doar animais confiscados para zoológicos ou aquários, entretanto, esta opção está se tornando pouco viável, uma vez que estes espaços não podem acomodar as grandes quantidades de animais que são disponibilizados (IUNC, 2000).

Sobre a terceira questão, pudemos perceber que os estudantes evidenciam a importância da visita para ampliar seus conhecimentos, inferimos, a partir daí, que a relação entre a teoria e prática é extremamente positiva, sendo assim, os espaços não formais constituem-se um importante elemento para favorecer a construção sólida do conhecimento.

Com os resultados obtidos na quarta questão, devemos concordar com Auricchio (1999), quando afirma que se verifica uma forte tendência conservacionista dos zoológicos, em transformar o seu espaço em grandes centros com a estruturação similar aos ecossistemas naturais. 
Em relação à quinta e sexta questões, a partir das respostas, são evidenciadas a percepção dos estudantes em relação aos animais, bem como a consolidação dos conhecimentos construídos no ambiente formal.

Sendo assim, os resultados foram significativos, uma vez que foram obtidas respostas consideradas corretas e que apresentaram argumentações coerentes. Nos relatórios posteriormente solicitados, pudemos perceber também que os estudantes foram sensibilizados a respeito do perigo de manter espécies selvagens em casa, e que a zoologia não se restringe apenas a nomenclatura, muito pelo contrário, estudar a zoologia é entender a história de todos nós, de como surgimos e de como evoluímos.

\section{Conclusões}

De acordo com os resultados observados, podemos concluir que, as aulas expositivas dialogadas, discussões e a vivência no espaço não-formal, proporcionaram aumento significativo na construção do conhecimento dos estudantes em relação as temáticas que envolvem a Zoologia e que foram abordadas durante este período de atividades.

Dessa forma, a excursão didática foi de grande relevância para a construção do conhecimento dos estudantes, pois, eles perceberam que os conteúdos teóricos estão conectados com a realidade extraescolar, assim, solidificamos esse conhecimento de forma eficiente, uma vez que foi contextualizado e discutido, tendo em vista a própria vivência deles. Dessa forma, acreditamos que as visitas em espaços não-formais de educação dinamizam o conhecimento, tornando-o ainda mais instigante e motivador, podendo assim promover e fortalece o processo de ensino-aprendizagem para que ele se torne efetivo e significativo.

\section{Referências}

ACHUTTI, M, R, N, G. O zoológico como um ambiente educativo para vivenciar o ensino de ciências. Itajaí, 2003. 20 p. Dissertação (programa de mestrado acadêmico em Educação). Centro de Educação, Universidade do Vale do Itajaí, 2003.

AURICCHIO, A. L. R. Potencial de la Educación Ambiental en los Zoológicos Brasileños. Instituto Pau Brasil de História Natural: São Paulo, 1999.

BRANDÃO, C, R. O que é educação. São Paulo: Brasiliense, 1985.

CHASSOT, A. Alfabetização Científica, Questões e desafios para a educação. Rio Grande do Sul: Ijuí, 2003. 
Diretrizes da IUCN sobre a disposição de animais confiscados <http://iucn.org/themes/ ssc/pubs/policy/index.htm\#anchor298469> acessado em: 07 agost. 2016.

ELIAS, D,C,N; AMARAL, L, H; ARAÚJO, M, S, T. Criação de um espaço de aprendizagem significativa no planetário do parque Ibirapuera. Revista Brasileira de Pesquisa em Educação em Ciências: Minas gerais, 2007.

JACOBUCCI, D, F, C. Contribuições dos espaços não formais de educação para a formação da cultura científica. Em extensão: Uberlândia, 2008.

KRASILCHIK, M. Perspectivas para o ensino de Biologia. 4ª ed. São Paulo: EDUSP, 2005.

MARANDINO, M; SELLES, S; FERREIRA, M. Ensino de Biologia, Histórias e práticas em diferentes espaços educativos. São Paulo: Cortez, 2009.

PRAIA, J;GIL-PEREZ, D; VILCHES, A. O papel da natureza da ciência na educação para a cidadania. Ciências \& Educação: Bauru, 2007.

Secretaria de Meio Ambiente e Sustentabilidade - Parque Estadual de Dois Irmãos - Governo de Pernambuco 〈http://www.portaisgoverno.pe.gov.br/web/parque-dois-irmaos/os-animais> Acessado em: 6 out. 2016.

SONIA, L; ROSSO, S. Bio: Volume 01. $3^{\circ}$ Ed. São Paulo: Saraiva, 2014. 